\title{
Pressure injury prevention for surgery: Results from a prospective, observational study in a tertiary hospital
}

Follow this and additional works at: https://www.journal.acorn.org.au/jpn

Part of the Health Services Administration Commons, Health Services Research Commons, Perioperative, Operating Room and Surgical Nursing Commons, and the Surgery Commons

(c) (i)

This work is licensed under a Creative Commons Attribution 4.0 License.

\section{Recommended Citation}

Wang, Isabel; Walker, Rachel; and Gillespie, Brigid M. (2018) "Pressure injury prevention for surgery: Results from a prospective, observational study in a tertiary hospital," Journal of Perioperative Nursing: Vol. 31 : Iss. 3 , Article 4.

Available at: https://doi.org/10.26550/2209-1092.1035

https://www.journal.acorn.org.au/jpn/vol31/iss3/4

This Article is brought to you for free and open access by Journal of Perioperative Nursing. It has been accepted for inclusion in Journal of Perioperative Nursing by an authorized editor of Journal of Perioperative Nursing. 


\section{Authors \\ Isabel Wang \\ BN (Hons), RN \\ School of Nursing and Midwifery, Griffith \\ University, Gold Coast, Queensland, \\ Australia \\ Dr Rachel Walker \\ PhD, RN \\ School of Nursing and Midwifery, Menzies \\ Pressure injury prevention for surgery: Results from a prospective, observational study in a tertiary hospital}

Health Institute, Griffith University,

Nathan Campus, Queensland, Australia

Division of Surgery, Princess Alexandra

Hospital, Queensland, Australia

Professor Brigid M Gillespie

PhD, RN, FACORN

School of Nursing and Midwifery, Griffith

University, Gold Coast, Queensland,

Australia

Gold Coast Hospital and Health Service,

Queensland, Australia

\section{Corresponding author}

Professor Brigid M Gillespie

PhD, RN, FACORN

School of Nursing and Midwifery, Griffith

University, Gold Coast, Queensland,

Australia

Gold Coast Hospital and Health Service,

Queensland, Australia

b.gillespie@griffith.edu.au

Implementing pressure injury prevention in a perioperative setting

\section{Background}

Hospital acquired pressure injury (HAPI) refers to the development of pressure injury $(\mathrm{PI})$ during hospitalisation. Prevalence rates of HAPI among all PI cases in acute health settings vary widely in different regions and countries, ranging from three to 18 per cent $\mathrm{t}^{1-12}$. While patients with limited mobility are at greater risk of developing a PI, anaesthetised patients are particularly vulnerable due to limited mobility. Perioperative HAPI remains problematic, with current prevalence rates varying from 5.1 to 64.1 per cent ${ }^{13}$. Through the literature review component of this study, we identified five categories of pressure injury prevention (PIP) strategies that comply with current clinical practice guidelines ${ }^{14}$. There has been considerable research undertaken on PIP in medical-surgical wards but research undertaken in the perioperative environment is scarce ${ }^{15}$.

\section{Study aim}

The aim of this study was to report on the PIP strategies used by perioperative health professionals at a large tertiary hospital in southeast Queensland.

\section{Method}

This is an observational study of the use of PIP strategies by health care professionals across a selected range of surgical procedures in a tertiary hospital. A structured data collection tool was developed, tested and used to collect patients' demographic and clinical data, and health care professionals' implementation of PIP strategies, as well as data from skin inspection on day two after surgery. Observations occurred during the preoperative, intra-operative and post-operative periods, i.e. in the induction room, in the operating room and during the first half hour after the patient was admitted to the Post Anaesthesia Care Unit (PACU) respectively. The study was conducted in 2016.

\section{Setting and sample}

The study setting was a 750-bed tertiary hospital in Queensland. Surgical procedures were purposively selected across seven specialties. Adult patients whose length of surgery exceeded 60 minutes and who were anticipated to be an inpatient for a minimum of 48 hours after surgery were included in the study. All perioperative practitioners working in the operating room department were invited to participate. Patients who were unable to provide informed consent and who could not speak, read or understand English in the absence of an interpreter were excluded from the study.

\section{Results}

In total, this study recruited and observed 278 staff during surgical procedures of 73 recruited patients. Table 1 presents patients' characteristics by surgical specialty. Each specialty group had at least ten 
Table 1: Patient characteristics by surgical specialty $(n=73)$

\begin{tabular}{|c|c|c|c|c|c|c|c|c|c|c|c|c|c|c|c|}
\hline \multicolumn{3}{|c|}{$\begin{array}{l}\text { Surgical specialty } \\
\text { (Frequency and } \\
\text { percentage of total } \\
\text { patient sample) }\end{array}$} & \multicolumn{2}{|c|}{$\begin{array}{c}\text { Age } \\
\text { (Median } \\
\text { and IQR of } \\
\text { total patient } \\
\text { sample) }\end{array}$} & \multicolumn{3}{|c|}{$\begin{array}{c}\text { Gender } \\
\text { (Frequency and } \\
\text { percentage of } \\
\text { specialty group) }\end{array}$} & \multicolumn{2}{|c|}{$\begin{array}{c}\text { Comorbidities } \\
\text { (Median } \\
\text { and IQR of } \\
\text { total patient } \\
\text { sample) }\end{array}$} & \multicolumn{2}{|c|}{$\begin{array}{l}\text { Waterlow risk } \\
\text { groups }^{\dagger} \\
\text { (Median } \\
\text { and IQR of } \\
\text { total patient } \\
\text { sample) }\end{array}$} & \multicolumn{2}{|c|}{$\begin{array}{l}\text { Length of } \\
\text { surgery (in } \\
\text { minutes) } \\
\text { (Median } \\
\text { and IQR of } \\
\text { total patient } \\
\text { sample) }\end{array}$} & \multicolumn{2}{|c|}{$\begin{array}{l}\text { Temperature } \\
\text { at PACU } \\
\text { admission } \\
\text { (Median } \\
\text { and IQR of } \\
\text { total patient } \\
\text { sample) }\end{array}$} \\
\hline & $\mathrm{n}$ & $\%$ & Median & IQR & & $n$ * & $\%$ & Median & IQR & Median $^{t+}$ & $\mathrm{IQR}$ & Median & IQR & Median & IQR \\
\hline Cardiac & 10 & 13.7 & 60.0 & 21.75 & male & 8 & 80 & 4.5 & 7.25 & 4.00 & 1.25 & 302.5 & 141.75 & 36.40 & 0.00 \\
\hline Neurology & 10 & 13.7 & 66.0 & 27.75 & female & 7 & 70 & 4.5 & 4.25 & 1.00 & 2.00 & 215.5 & 132.75 & 36.00 & 0.80 \\
\hline Orthopaedic & 12 & 16.4 & 63.0 & 19.50 & male & 7 & 58 & 3.5 & 4.50 & 1.00 & 1.00 & 115.5 & 55.25 & 36.45 & 0.45 \\
\hline Gynaecology & 11 & 15.1 & 52.0 & 22.00 & female & 11 & 100 & 4.0 & 1.75 & 1.00 & 4.00 & 181.0 & 62.00 & 36.10 & 0.40 \\
\hline General & 10 & 13.7 & 75.5 & 18.50 & male & 6 & 60 & 4.0 & 4.25 & 1.00 & 3.00 & 268.5 & 167.00 & 36.30 & 1.05 \\
\hline Vascular & 10 & 13.7 & 70.5 & 16.75 & male & 7 & 70 & 5.0 & 4.50 & 1.00 & 2.25 & 151.5 & 52.25 & 36.20 & 0.42 \\
\hline Urology & 10 & 13.7 & 69.00 & 14.50 & male & 8 & 80 & 4.00 & 5.50 & 0.00 & 1.75 & 150.5 & 138.00 & 36.15 & 0.42 \\
\hline
\end{tabular}

* $\mathrm{n}$ reports only the dominant gender per specialty group.

† 18 incomplete Waterlow risk assessments were excluded, as only 15 per cent of the items were complete, on average.

†† 1 to 3 refers to at-risk, moderate-risk and high-risk groups, respectively; 0 refers to not-at-risk group; 4 refers to unavailable or incomplete Waterlow assessment.

${ }^{\wedge}$ In 11 cases data for temperature upon PACU admission was missing, as this was not recorded when the patients arrived at the PACU.

patients, and their age, comorbidities, Waterlow risk assessment scores, length of surgery, and temperature upon PACU admission are reported using the median and IQR.

Data about selected PIP strategies were derived through observation or documentation; as shown in Table 2, most data was derived from direct observation. Data for three selected categories of PIP strategies - skin inspection, positioning aids and medical devices or/and equipment were collected from direct observation, and data for selected interprofessional communication strategies were collected from both observation and documentation when communication was related to skin inspection, positioning and medical devices or/and equipment ( $n=10 / 90,55.6$ per cent). Data for selected communication strategies where communication was related to
Table 2: Sources of data for each key PIP strategy category $(n=90)$

\begin{tabular}{|l|c|c|c|}
\hline Category of PIP & $\begin{array}{r}\text { Number of } \\
\text { PIP strategies } \\
\text { implemented* }\end{array}$ & $\begin{array}{r}\text { Data for PIP } \\
\text { strategy collected } \\
\text { from observation } \\
n(\%)\end{array}$ & $\begin{array}{r}\text { Data for PIP } \\
\text { strategy } \\
\text { collected from } \\
\text { documentation } \\
n(\%)\end{array}$ \\
\hline Skin inspection & 6 & $6(100)$ & $0(0)$ \\
\hline Positioning aids & 18 & $18(100)$ & $0(0)$ \\
\hline $\begin{array}{l}\text { Medical devices } \\
\text { or/and equipment }\end{array}$ & 34 & $34(100)$ & $2(14.3)$ \\
\hline Thermal regulation & 14 & $12(85.7)$ & $10(55.6)$ \\
\hline $\begin{array}{l}\text { Interprofessional } \\
\text { communication }\end{array}$ & 18 & $8(44.4)$ & 12 \\
\hline $\begin{array}{l}\text { Total number of } \\
\text { PIP strategies }\end{array}$ & 90 & 78 & 0 \\
\hline
\end{tabular}

*Each category includes a number of PIP strategies. For instance, preoperative, intraoperative and post-operative skin integrity screening are three strategies in the skin inspection category. 


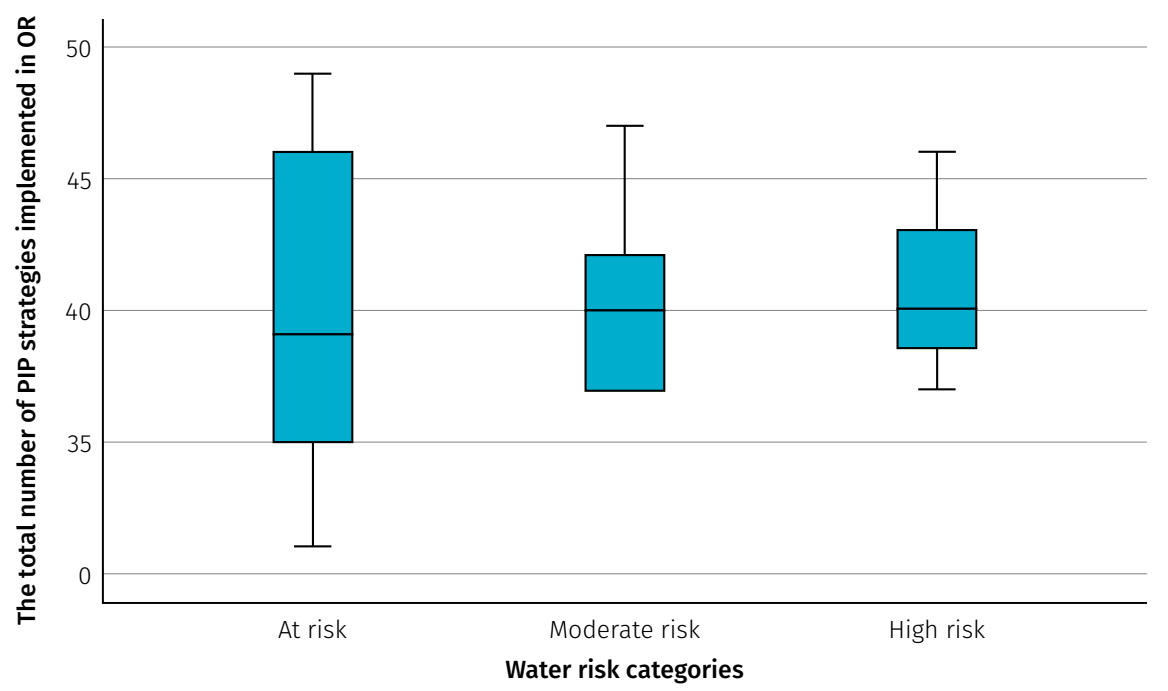

Figure 1: Box plots of the total number of PIP strategies implemented during the intraoperative period with whiskers from minimum to maximum for the three Waterlow risk categories $(n=36)$

thermal regulation was drawn from documentation when it was related to patients' temperature measured upon PACU admission ( $n=2 / 90,14.3 \%)$.

Figure 1 is a box plot that illustrates the number of PIP strategies implemented, based on patients' PI risk. Of the 36 patients deemed to be at risk of developing PI using the Waterlow risk assessments, the median number of PIP strategies implemented intra-operatively ranged from 39 to 40 strategies for the three risk groups - at risk, moderate risk, high risk (IQR = 11.5, 6.5 and 3, respectively). The results suggest that the highest number of PIP strategies was implemented for patients in the at-risk category. The minimum total number of PIP strategies implemented for patients in the moderate and high-risk groups was higher than for patients in the at-risk group, although the difference was not statistically significant ( $p=0.819$ ).

\section{Sub-analysis}

A high incidence rate of $\mathrm{PI}$ on day two after surgery has been reported in the literature ${ }^{16,17}$. Hence, the decision to inspect patients' skin on the second post-operative day was made. In this study, skin inspection on the second day after surgery revealed that four male cardiac surgical patients had developed a postoperative Stage $1 \mathrm{PI}$ on the ear, due to pressure from oxygen tubing.

As shown in Table 3 these patients had a median age of 70 years (IQR: 22 years, range: $55-79$ years) and were all either overweight or obese. Two patients had more than eight comorbidities, and three had an American Society of Anesthesiologists (ASA) score of 4, indicating severe systemic disease that is a constant threat to life $^{18}$. Prior to induction, a Waterlow risk assessment was not completed for three of these patients (75 per cent). The median length of surgery for this group was 302 minutes, over five hours (IQR = 162.5 minutes, range: $201-410$ minutes). The primary surgical position used in all four cases was supine.
Table 3: Sub-analysis for patients who had PI on day two after surgery $(n=4)$

\begin{tabular}{|c|c|c|c|}
\hline \multicolumn{2}{|l|}{ Factors } & & $\mathrm{n}(\%)$ \\
\hline \multirow{13}{*}{$\begin{array}{l}\text { Demographic } \\
\text { factors }\end{array}$} & \multirow[t]{2}{*}{ Age } & 47-70 years & $2(50)$ \\
\hline & & $>71$ years & $2(50)$ \\
\hline & \multirow[t]{3}{*}{ Number of comorbidities } & $0-3$ & $1(25)$ \\
\hline & & $4-8$ & $1(25)$ \\
\hline & & $>8$ & $2(50)$ \\
\hline & \multirow[t]{2}{*}{ BMI } & $25.0-29.9$ & $2(50)$ \\
\hline & & $\geq 30.0$ & $2(50)$ \\
\hline & \multirow[t]{2}{*}{ Waterlow scores } & $\geq 20$ & $1(25)$ \\
\hline & & N/A or incomplete & $3(75)$ \\
\hline & \multirow[t]{2}{*}{ ASA status } & ASA 3 & $1(25)$ \\
\hline & & ASA 4 & $3(75)$ \\
\hline & \multirow{2}{*}{$\begin{array}{l}\text { Number of medications } \\
\text { taken before induction }\end{array}$} & $0-2$ & $3(75)$ \\
\hline & & $3-6$ & $1(25)$ \\
\hline \multirow[t]{3}{*}{ Clinical factors } & \multirow[t]{2}{*}{ Length of surgery } & 181-300 minutes & 50 \\
\hline & & > 300 minutes & 50 \\
\hline & Primary surgical position * & supine & $4(100)$ \\
\hline
\end{tabular}

* The patient may be repositioned intra-operatively; however, the position in which the patient spent the most time was documented. 


\section{Key messages}

The total number of PIP strategies used intra-operatively and Waterlow risk assessment scores suggests that patient deemed to be at risk (using the Waterlow risk assessment tool) have a higher number of PIP strategies implemented intraoperatively.

Patients having prolonged surgeries, i.e. greater than two hours, are at greater risk of developing a PI.

Post-operative PIs that occur as a result of using medical devices or equipment should not be overlooked. Perioperative professionals should be vigilant and monitor the use of devices and equipment during the intra-operative period.

\section{References}

1. Cuddigan J, DR Berlowitz, EA Ayello. (2001). Pressure ulcers in America: Prevalence, incidence, and implications for the future. Adv Skin Wound Care 2001;14(4):208-215.

2. Chan EY, Tan SL, Lee CK, Lee JY. Prevalence, incidence and predictors of pressure ulcers in a tertiary hospital in Singapore. I Wound Care 2005;14(8):383-384,386-388.

3. Reddy M, Gill SS, Rochon PA. Preventing pressure ulcers: A systematic review. JAMA 2006;296(8):974-984.
4. Victoria Department of Health. PUPPS3 Pressure ulcer point prevalence survey: Statewide report 2006. Melbourne: Victoria Department of Health; 2006.

5. South Australia Department of Health. South Australia pressure ulcer point prevalence survey report 2007. Adelaide: South Australia Department of Health; 2007.

6. Sanada HY, Miyachi T, Ohura T, Moriguchi K, Tokunaga K, Shido et al. The Japanese pressure ulcer surveillance study: A retrospective cohort study to determine prevalence of pressure ulcers in Japanese hospitals. Wounds 2008;20(6):176-182.

7. VanGilder C, Amlung S, Harrison P, Meyer S. Results of the 2008-2009 international pressure ulcer prevalence survey and a three-year, acute care, unit-specific analysis. Ostomy Wound Manage 2009;55(11):39-45.

8. Mulligan S, Scott L, Prentice J, Elmes R, Carville K, Santamaria N. WoundsWest Wound prevalence survey 2009: State-wide report. Perth: Ambulatory Care Services, Department of Health; 2009.

9. Lyder CH, Wang Y, Metersky M, Curry M, Kliman R, Verzier NR. Hospital-acquired pressure ulcers: Results from the national Medicare Patient Safety Monitoring System study. J Am Geriatr Soc 2012;60(9):1603-1608.

10. Bergquist-Beringer SL, Dong L, He J, Dunton N. Pressure ulcers and prevention among acute care hospitals in the United States. Jt Comm J Qual Patient Saf 2013;39(9):404-414.

11. Mallah Z, Nassar N, Kurdahi Badr L. The effectiveness of a pressure ulcer intervention program on the prevalence of hospital acquired pressure ulcers: Controlled before and after study. Appl Nurs Res 2015;28(2):106-113.
12. Queensland Health. Queensland bedside audit. Brisbane: Queensland Health; 2016.

13. Shafipour V, Ramezanpour E, Gorji MA, Moosazadeh M. Prevalence of postoperative pressure ulcer: A systematic review and meta-analysis. Electron Physician 2016;8(11):3170-3176.

14. National Pressure Ulcer Advisory Panel (NPUAP), European Pressure Ulcer Advisory Panel (EPUAP) and Pan Pacific Pressure Injury Alliance (PPPIA). Prevention and treatment of pressure ulcers: Quick reference guide. Emily Haesler (Ed.). Cambridge Media: Perth, Australia; 2014.

15. Wang HM, Walker R, Gillespie BM. How well do perioperative practitioners implement pressure injury prevention guidelines? A brief report. Wound Pract Res 2018;26(1):24-33.

16. Schuurman JP, Schoonhoven L, Keller $B P$, van Ramshorst B. Do pressure ulcers influence length of hospital stay in surgical cardiothoracic patients? A prospective evaluation. J Clin Nurs 2009;18(17):2456-2463.

17. Connor T, Sledge JA, Bryant-Wiersema L, Stamm L, Potter P. Identification of preoperative and intra-operative variables predictive of pressure ulcer development in patients undergoing urologic surgical procedures. Urol Nurs 2010;30(5):289.

18. American Society of Anesthesiologists (ASA). ASA physical status classification system. Washington D.C.: ASA; 2014 [cited 2017 November 11]. Available from: www.asahq. org/resources/clinical-information/asaphysical-status-classification-system. 